\title{
MEIO AMBIENTE VERSUS EMPREGO: IMPACTOS DE TRANSFORMAÇÕES TECNOLÓGICAS NA OCUPAÇÃO CANAVIEIRA NO ESTADO DE SÃO PAULO, BRASIL, 2007 A 2013
}

\author{
José Giacomo Baccarin ${ }^{1}$ \\ Denise Boito Pereira da Silva ${ }^{2}$
}

\begin{abstract}
Resumo: Analisam-se motivações sociais e empresariais das recentes mudanças tecnológicas na lavoura canavieira no Estado de São Paulo e suas consequências na ocupação canavieira. Usaram-se dados do Programa de Disseminação de Estatísticas do Trabalho do Ministério do Trabalho e Emprego do Brasil. Destaca-se, pós 2007, a rápida substituição da colheita manual de cana queimada pela colheita mecânica de cana crua, bem como a ampliação do plantio mecânico. Com isso, os danos ambientais foram reduzidos, ao mesmo tempo, que o número de Trabalhadores Canavieiros caiu praticamente à metade e houve queda de sua sazonalidade de ocupação no ano, embora ela continue muito alta. A participação relativa das mulheres e dos mais velhos aumentou entre os Canavieiros, bem mais que nas demais ocupações sucroalcooleiras.
\end{abstract}

Palavras Chaves: Trabalhador Canavieiro, Mecanização Agrícola, Ocupação Agrícola.

\begin{abstract}
We analyzed social and enterprise motivations of recent technological changes in the sugarcane plantations in São Paulo state and its consequences in the sugarcane occupation. We used data from the Program of Work Statistics Dissemination of the Ministry of Labor and Employment of Brazil. It stands out the rapid replacement of manual harvesting of burnt cane by mechanical harvesting of raw cane, as well as the expansion of mechanical planting. With this, the environmental damage fell, the number of sugarcane workers dropped almost in half and there was a decrease of its seasonality occupation in the year. The presence of women and older increased between sugarcane workers, much more than in other sugarcane occupations.
\end{abstract}

Key words: Sugarcane Worker, Agricultural Mechanization, Agricultural Occupation.

\footnotetext{
Agrônomo, com Mestrado em Economia Agrária ESALQ/USP, Doutorado em Engenharia de Produção UFSCAR, Professor Doutor do Departamento de Economia Rural da Faculdade de Ciências Agrárias e Veterinárias, UNESP, campus de Jaboticabal. Rodovia Professor Paulo Donato Castellani, s. .., CEP 14.884-900, Jaboticabal (SP). E-mail: baccarin@fcav.unesp.br. Fone: 16 32092634, Ramal 227.

2 Agrônoma, mestre em Geografia pela UNESP Rio Claro. Bolsista DTI-B do CNPq. UNESP, campus de Jaboticabal. Rodovia Professor Paulo Donato Castellani, s. n., CEP 14.884-900, Jaboticabal (SP). E-mail: denise_bps@ @hotmail.com. Fone: 16 997742827.
} 


\section{1 - INTRODUÇÃO}

O presente século tem registrado dois fatos com efeitos sobre a ocupação da agropecuária brasileira. Um deles é a expansão da área e da produção de suas principais lavouras e criações, outro é a extensão da mecanização por todo o ciclo de diversas culturas temporárias e permanentes. Enquanto o primeiro tende a impactar positivamente, o segundo traz consequências negativas no nível de ocupação setorial.

A área plantada no Brasil com grãos (entre eles algodão, arroz, feijão, milho, soja e trigo) passou de 37,82 milhões de hectares na safra $1999 / 2000$ para 53,26 milhões de hectares em 2012/13, crescimento de $40,8 \%$, enquanto sua produção se elevava de 83,03 milhões de toneladas para 186,82 milhões de toneladas, aumento de $125,0 \%$ (CONAB, 2013). Fortes expansões também foram verificadas na produção de outras lavouras, como cana-de-açúcar, café e laranja. No caso da cana-de-açúcar, a produção brasileira passou de 310,12 milhões de toneladas em 1999/2000 para 588,92 milhões de toneladas em 2012/13, ou $89,9 \%$ a mais (CONAB, 2013a).

Nas principais atividades pecuárias registraram-se os seguintes índices de crescimento da produção entre 2000 e 2012: 124,4\% na carne bovina, $63,4 \%$ no leite de vaca, $111,6 \%$ na carne de frango, $38,1 \% \mathrm{em}$ ovos de galinha e $36,3 \%$ na carne suína (IBGE, 2013). Todos, portanto, muito expressivos.

Contudo, esse crescimento vem sendo acompanhado de mudanças tecnológicas significativas, especialmente nas lavouras e florestas plantadas, com a mecanização se ampliando em área e atingindo etapas da produção, que até pouco tempo atrás eram feitas de forma manual, predominantemente. Isso se deu, por exemplo, no plantio de café, cana-de-açúcar e eucalipto, bem como na colheita dessas culturas e do algodão e amendoim. Assim, a extensão da mecanização por todo o ciclo produtivo, que já se verificava em culturas como o milho e a soja, se generalizou pela agricultura brasileira.

Os dados disponíveis revelam queda de ocupação agropecuária. Segundo o Censo Agropecuário 2006 (IBGE, 2009), o número de pessoas ocupadas na agropecuária brasileira passou de 23,4 milhões em 1985, para 17,9 milhões em 1996 e para 16,4 milhões em 2006. Já os dados da Pesquisa Nacional por Amostra de Domicílio (PNAD), para um período mais recente, informam que a ocupação agropecuária, depois de crescer de 15.822 mil pessoas em 2001 para 18.100 mil pessoas em 2005, a partir daí apresentou tendência de redução chegando a 2013 com 13.982 mil 
pessoas ocupadas, o que representa apenas $14,5 \%$ do total da ocupação brasileira (IBGE, 2014).

Especificamente para o Estado de São Paulo considera-se outro fator com efeito sobre a ocupação, qual seja a forma como vem evoluindo o uso da terra agrícola. Baccarin et al (2014) mostram que a grande expansão da área com cana-de-açúcar na década de 2000 se deu sobre a área de outras lavouras e, especialmente, sobre a área de pastagens. Este fato poderia ter contribuído para elevação da ocupação, dada a baixa necessidade de força de trabalho na pecuária bovina. Contudo, não se deve desconsiderar que, com se verá mais adiante, a mecanização do plantio e da colheita da cana-de-açúcar se acentuaram no período mais recente, pós 2007, diminuindo a contribuição dessa cultura para geração de postos de trabalho. Dados da PNAD mostram que entre 2007 e 2012 a ocupação na agropecuária paulista reduziu-se de 987.082 para 727.047 pessoas, enquanto a ocupação na lavoura canavieira caía de 195.679 para 167.388 pessoas (LIMA, 2014).

O presente artigo usa outros dados sobre ocupação, quais sejam, os de ocupação formal (com carteira de trabalho assinada), colhidos e sistematizados pelo Ministério do Trabalho e Emprego (MTE). A partir disso e com base em revisão de literatura, analisam-se causas e quantifica-se a evolução do número de Trabalhadores Canavieiros no Estado de São Paulo entre 2007 e 2013, registrando também sua importância em relação a outras ocupações sucroalcooleiras e sua sazonalidade de ocupação no ano. Adicionalmente, discutem-se algumas das consequências da desocupação e verificam-se alterações na composição de gênero e na faixa etária desses trabalhadores.

Entende-se como Trabalhador Canavieiro aquele dedicado a atividades agrícolas que não exigem maior qualificação profissional, como o plantio e a colheita manual de cana-de-açúcar.

$\mathrm{Na}$ segunda seção são descritas as recentes mudanças tecnológicas canavieiras, especialmente a mecanização de sua colheita, destacando alguns de seus condicionantes sociais e econômicos, bem como se discorre sobre a expansão da produção setorial. A terceira seção apresenta a forma como foram obtidos e trabalhados os dados de ocupação, a evolução de seu número entre 2007 e 2013 vis a vis as demais ocupações sucroalcooleiras e questões ligadas à desocupação dos Canavieiros. $\mathrm{Na}$ quarta seção estudam-se as mudanças na participação dos gêneros e nas faixas etárias dos Trabalhadores Canavieiros entre 2007 e 2013. Algumas considerações finais encerram o trabalho. 


\section{2 - A GENERALIZAÇÃO DA MECANIZAÇÃO CANAVIEIRA}

No final da década de 1990 registrava-se importante debate social em torno do método da colheita de cana-de-açúcar, contrapondo, em uma primeira aproximação, posições que apregoavam a necessidade de diminuir os danos ambientais e as que defendiam a manutenção do nível de ocupação canavieira.

Em 1997, segundo Paes (2007), o método amplamente predominante do corte de cana-de-açúcar no Estado de São Paulo era o manual, constatado em $86 \%$ dos canaviais. Excetuando uma pequena parcela, entre 1 e $2 \%$, de cana colhida crua para o plantio, o restante da colheita manual era feito após a queimada da palha da cana-de-açúcar.

A queimada dos canaviais tinha se generalizado a partir dos anos 1960, quando a implantação do carregamento mecânico da cana cortada estimulou o aumento da produtividade do seu corte, que pode ser alcançado com aquela prática. Estimativas correntes dão conta que a queimada faz com que o cortador dobre ou mesmo triplique a quantidade de cana cortada diariamente (BACCARIN \& GEBARA, 2010).

A queimada trazia evidentes danos ambientais, atingindo a fauna e a flora e poluindo o ar. Resultava em problemas de saúde aos canavieiros e, segundo algumas interpretações, aos moradores das cidades próximas. Estes, aliás, eram obrigados a conviver com a sujeira urbana provocada pela fuligem da queimada trazida pelas correntes de ar.

Mobilizações sociais passaram a apregoar o fim imediato da queimada, o que encontrava respaldo na ação de parte do Ministério Público paulista que ingressava com ações judiciais prevendo a sua imediata eliminação.

Por seu lado, os empresários sucroalcooleiros afirmavam que os danos da queimada não seriam tão significativos e, ao mesmo tempo, diziam que sua prática era fundamental para garantir a ocupação dos milhares de canavieiros no corte de cana-de-açúcar ${ }^{3}$. Como não seria mais possível a volta da colheita manual de cana crua, o fim da queimada, necessariamente, viria acompanhada da implantação de sua colheita mecânica.

Gonçalves e Souza (1998, p. 35) estimaram que, em diferentes cenários, a mecanização do corte de cana significaria desempregar entre $18,8 \%$ e $64,9 \%$ dos trabalhadores canavieiros, correspondente de $10,7 \%$ a $29,3 \%$ de toda a ocupação da agropecuária paulista. 
Sob o ponto de vista da gestão empresarial, com auxílio de Veiga Filho (1998), pode-se especular que o volumoso investimento necessário, em momento de baixa rentabilidade setorial, e a não comprovação taxativa de vantagens de custo inibiam, naquela ocasião, que a colheita mecânica se generalizasse nos canaviais paulistas ${ }^{4}$.

Ressalte-se que o pagamento do corte de cana por produção diária, em vigor desde sempre, era e continua sendo uma forma de aumentar o controle dos empresários sobre o ritmo de trabalho dos cortadores de cana. De certa forma, isso substituía o controle de ritmo que seria obtido pelo uso do maquinário.

Outra especulação a ser feita toma por base o fato de que em 1997, ainda segundo Paes (2007), dos 14\% dos canaviais paulistas colhidos mecanicamente, em $10 \%$ usava-se previamente a prática da queimada e em apenas $4 \%$ a cana era colhida crua. Era possível, portanto, que a decisão da ampliação da mecanização, levando em conta apenas os interesses empresariais, trilhasse o caminho da colheita mecânica de cana queimada, agredindo ao meio ambiente e promovendo desocupação simultaneamente.

Contudo, foram sendo elaboradas legislações determinando que a prática da queimada dos canaviais fosse eliminada gradativamente, ainda que em período de tempo relativamente longo. Assim, no âmbito federal, como destaca Oliveira (1999), foi publicado o Decreto 2.661 de 8 de julho de 1998 estabelecendo que a prática da queimada da palha da cana deveria ser eliminada em 20 anos 5 .

No Estado de São Paulo havia sido aprovado o Decreto n. 42.056, de 6 de agosto de 1997, estabelecendo que a queimada da palha da cana deveria ser extinta, em áreas mecanizáveis (com declividade igual ou inferior a 12\%), em prazo máximo de oito anos e, em área não mecanizáveis (declividade superior a 12\%), em 15 anos (OLIVEIRA, 1999). Imediatamente, houve reação empresarial contrária e novas propostas passaram a ser discutidas na Assembleia Legislativa do Estado de São

"Em resumo, as relações de preços fator/produto, os níveis exigidos de investimentos e as comparações de custos, atuando pelo lado da demanda por tecnologia, não emitiram sinais claros e incisivos no sentido da substituição de mão-de-obra por tecnologia poupadora desse recurso no período estudado." (VEIGA FILHO, 1998, p. 19)

5 "Desde a década de 60, o governo federal vem criando algumas diretrizes para a questão das queimadas no Brasil, as quais estabelecem a prática controlada do fogo em atividades agropastoris ou florestais. Recentemente, criou o Decreto no. 2.661, de 8 de julho de 1998, que regulamenta o parágrafo único do art. 27 da Lei no. 4.771, de 15 de setembro de 1965 (Código Florestal) estabelecendo, no cap. IV, art. 16, sobre a redução gradativa do fogo, que: 'O emprego do fogo, como método despalhador e facilitador do corte de cana-de-açúcar em áreas passíveis de mecanização da colheita, será eliminado de forma gradativa, não podendo a redução ser inferior a um quarto da área mecanizável de cada unidade agroindustrial ou propriedade não vinculada a unidade agroindustrial, a cada período de cinco anos, contados da data da publicação deste decreto." (OLIVEIRA, 1999, p. 2) 
Paulo. Acabou-se por editar a Lei 11.241, de 19/09/2002 (ALESP, 2012), prevendo a eliminação completa da queimada dos canaviais até 2031, em áreas não mecanizáveis ou em imóveis menores que 150 hectares, e até 2021 , em áreas mecanizáveis.

Portanto, de acordo com os interesses dos empresários sucroalcooleiros no início do presente século, a legislação ora em vigor no Estado de São Paulo mostra-se bastante elástica e cautelosa, estabelecendo prazos de 20 a 30 anos, a partir de 2002, para a eliminação total da queimada da palha de cana em seu território.

Contudo, por volta de 2006 , foi se verificando alteração na posição empresarial. À época as possibilidades de exportação de etanol tinham aumentado e a manutenção da prática da queimada poderia servir como barreira não tarifária a ser usada para dificultar a compra da produção brasileira por parte de alguns países, especialmente da União Europeia ${ }^{6}$. Nesse ano, a área de cana colhida mecanicamente no Estado havia se elevado para $38 \%$, sendo $9 \%$ de cana queimada e $29 \%$ de cana crua (PAES, 2007).

Tinham contribuído para esse avanço da colheita mecânica as adaptações que se realizaram nos canaviais, com talhões mais compridos e regulares, a melhoria de preços do açúcar e etanol, a partir de 2001, aumentando a capacidade de investimentos empresariais ${ }^{7}$, e as evidências que os custos de produção da colheita mecânica iam se mostrando mais competitivos em relação aos da colheita manual ${ }^{8}$.

O discurso empresarial incorporou essas novas condições, substituindo a defesa da ocupação dos trabalhadores canavieiros pela necessidade de se adotarem medidas de proteção ambiental, entre elas a redução mais rápida da queimada dos canaviais. Um fato que evidencia essa mudança de atitude foi a promulgação do Protocolo Agroambiental, em 2007, no Estado de São Paulo, envolvendo a União da Indústria de Cana-de-açúcar (UNICA), associações de fornecedores e as Secretarias Estaduais do Meio Ambiente e

\footnotetext{
Oliveira (1999) já destacava, na década de 1990, que empresas sucroalcooleiras ficavam sujeitas a maiores exigências ambientais, especialmente por parte dos países europeus, quando desejavam exportar seus produtos. Passava-se a requerer certificações ambientais, como o chamado Selo Verde. Isso se acentuou no Século XXI e, atualmente, várias empresas sucroalcooleiras divulgam o fato de terem obtido o Selo Bonsucro, o que comprovaria que adotam boas práticas ambientais e sociais (BONSUCRO, 2013).

7 Ramos (2007) aponta que, em 2003, foram vendidas no Brasil 40 colhedoras de cana-de-açúcar, número que saltou para 254, em 2006.

8 Três anos após, em 2009, estudo de Oliveira e Nachiluk (2011), para um universo grande de empresas e em seis regiões canavieiras de São Paulo, mostra que o custo do corte mecânico se mostrava entre 2,3\% e 17,0\% menor que o corte manual, de acordo com as diversas situações analisadas.
} 
da Agricultura e Abastecimento de São Paulo. Nele propunha-se a antecipação do final das queimadas da cana-de-açúcar no Estado para 2014, em áreas mecanizáveis, e para 2017, em áreas não mecanizáveis ou menores que 150 hectares, prazos mais exíguos do que os previstos na já citada Lei Estadual 11.241/2002 (FREDO et al, 2008).

Ainda que adesão pelos empresários ao Protocolo fosse voluntária, a partir de sua edição fica nítida a intensificação da mecanização do corte de cana-de-açúcar. Nesse sentido, documento da Secretaria de Meio Ambiente do Governo do Estado de São Paulo (SEMA/SP, 2013) informa que as empresas paulistas que aderiram ao Protocolo Agroambiental possuíam 753 colhedoras na safra 2006/07, passando para 2.740 máquinas na safra 2012/13.

Outros dados confirmam a aceleração do processo de mecanização. Informações do Projeto CANASAT (INPE, 2013) dão conta de que a área de cana queimada no Estado de São Paulo, em grande parte colhida manualmente, reduziu-se de 2.131 .990 hectares (65,8\% do total colhido) em 2006, para 1.277.004 ha em $2012(27,4 \%)$, enquanto a área de cana crua, em quase sua totalidade colhida mecanicamente, aumentava de 1.110 .120 ha $(34,2 \%)$ para 3.381 .311 ha $(72,6 \%$ do total colhido).

Existem outras indicações, mais diretas, sobre o avanço da colheita mecânica em São Paulo. Fredo et al (2012), com informações do Instituto de Economia Agrícola (IEA) da Secretaria de Agricultura e Abastecimento de São Paulo, estimam que, em 201 1, 69,8\% dos canaviais paulistas foram colhidos mecanicamente. Para a safra 2012, a UNICA (2013), com dados exclusivos das agroindústrias e não de fornecedores de cana, estima que a colheita mecânica atingiu 81,4\% dos canaviais de São Paulo. Pode-se supor que, em 2014, a colheita mecânica tenha se estendido para praticamente toda a área mecanizável do Estado e sob o controle direto de usinas e destilarias.

Um comentário adicional a esses dados é que não se pode estabelecer que o método de colheita mecânica seja exclusivo de cana crua. O Grupo IDEA (2012) e Braga Júnior (2012) estimam, respectivamente, que a colheita mecânica de cana queimada estava presente em 12,9\% em 2011 e 10,0\% em 2012 nos canaviais do Centro Sul do Brasil, em que se situam, com predominância, os canaviais de São Paulo.

O aumento expressivo da área de cana-de-açúcar colhida mecanicamente resulta em efeitos negativos no número de pessoas ocupadas nessa lavoura. Isto está sendo reforçado pelo acréscimo da produtividade média do cortador de cana. Assim, dados coletados pelo IEA para São 
Paulo mostram que, em 2000, o trabalhador canavieiro cortava, em média, 7,69 toneladas de cana por dia, passando para 8,93 toneladas por dia, em 2011, aumento de 16,1\% em 11 anos (IEA, 2012).

As empresas estabelecem metas e estimulam esse aumento de produtividade, o que reforça os problemas físicos e de saúde associados ao trabalho de corte de cana, por si mesmo já bastante desgastante (ALVES, 2007). Por sua vez, Silva (2005) chega a afirmar que o desgaste físico no corte de cana-de-açúcar leva a uma diminuição significativa na vida útil dos canavieiros.

Além da colheita, realizada normalmente entre abril e novembro, outra operação agrícola em que se observam modificações tecnológicas importantes em São Paulo é o plantio de cana, realizado, no mais das vezes, nos três primeiros meses do ano. Até alguns anos atrás, sua forma amplamente predominante era composta de operações mecanizadas e não mecanizadas. Entre as primeiras estavam o transporte das mudas, a abertura e o fechamento dos sulcos de plantio e a adubação. O semeio propriamente dito, que consiste na colocação da cana planta no solo para sua multiplicação, era feito manualmente. Grupos de trabalhadores, alojados em cima de caminhões, jogavam as canas nos sulcos, outros grupos as alinhavam e as picavam em pequenos toletes com auxílio de podões.

Embora com utilização de quantidade significativa de trabalhadores, o ritmo do plantio era ditado pelas máquinas, os caminhões que levavam as mudas e iniciavam a operação, os tratores que abriam previamente o sulco para realização do semeio e outros que adubavam e fechavam o sulco e terminavam a operação. Os trabalhadores não podiam se atrasar em relação ao ritmo de trabalho determinado pelo maquinário.

Mais recentemente, o plantio inteiramente mecânico de cana-deaçúcar está se alastrando. Braga Júnior (2012) informa que, em 2009, $33 \%$ do plantio de cana no Centro Sul foram totalmente mecanizados, valor que saltou para 57\%, em 2012.

Também aumentou o número de cortes de um mesmo canavial. $\mathrm{Na}$ década de 1970, o comum era que a cana fosse colhida cerca de 18 meses depois de plantada, sendo chamada de cana planta. Em seguida, deixavase brotar a soqueira desse canavial, que viria a ser colhido um ano após, obtendo-se a chamada cana soca. Por mais um ano, repetia-se a operação, obtendo-se a chamada cana ressoca. Depois do terceiro corte o canavial era renovado, com o revolvimento do solo, a incorporação das soqueiras antigas e a realização de novo plantio alguns meses depois. Ou seja, o plantio se repetia, no mesmo local, a cada quatro anos. 
Atualmente, devido ao melhoramento genético e aprimoramento nos tratos culturais, é comum que o mesmo canavial permita cinco ou seis cortes, antes da renovação. Assim, em uma mesma área, o plantio de cana se repete apenas a cada seis ou sete anos, diminuindo a necessidade de trabalhadores nessa operação. Isso não necessariamente diminui o número de pessoas ocupadas no conjunto de atividades canavieiras, posto que, mesmo sem fazer um novo plantio, a cana continua sendo colhida, ocupando trabalhadores nessa atividade.

Em suma, as mudanças tecnológicas vêm se aprofundando no cultivo da cana, especialmente na colheita. Já as modificações nas atividades industriais e administrativas se mostram menos abruptas que aquelas verificadas na década de 1990, quando, conforme Eid citado por Veiga Filho (1998), avançaram ações de informatização e automação industrial, bem como mudanças gerenciais em direção à menor burocracia, melhoria dos processos, redução de atividades hierárquicas e terceirização de uma série de serviços, resultando em diminuição no número de pessoas ocupadas nos escritórios, em atividades de apoio e no processamento industrial. Com isso, é de se esperar que esteja ocorrendo modificação no perfil da ocupação sucroalcooleira, com perda de importância de atividades que exigem menor qualificação profissional.

Quanto à expansão canavieira no Estado de São Paulo, a Tabela 1 mostra que houve arrefecimento de seu ritmo no período mais recente, em termos absolutos e relativos, tanto na área quanto na produção. De qualquer forma, a expansão produtiva entre 2007 e 2013 seria suficiente para estimular crescimento na ocupação, ao menos que os efeitos contrários das alterações tecnológicas, já descritos, tenham se revelado ainda mais intensos. É o que se verá na seção seguinte.

TABELA 1 - VARIAÇÃo dE ÁREA E PRODUÇÃO CANAVIEIRA NO Estado de Sĩo Paulo, 2001 a 2013.

\begin{tabular}{rcrrr}
\hline \multirow{2}{*}{ Período } & \multicolumn{2}{c}{ Variação Área (hectares) } & \multicolumn{2}{c}{ Variação Produção (toneladas) } \\
& Absoluta & Relativa & Absoluta & Relativa \\
\hline 2001 a 2007 & $1.826 .755,2$ & 60,7 & $126.000 .718,0$ & 62,5 \\
2007 a 2013 & $1.354 .544,8$ & 43,4 & $116.703 .906,6$ & 35,6 \\
\hline
\end{tabular}

Fonte: IEA (2014).

Antes de seguir adiante, contudo, julga-se importante explorar outro ponto da Tabela 1. Pode-se perceber que entre 2007 e 2013 a variação da área foi maior que a da produção, indicando que a produtividade canavieira, 
medida em toneladas/hectare, caiu nesse período. Em parte, isso tem sido atribuído a problemas climáticos. Mas, alguns têm destacado a influência negativa da rápida disseminação do plantio e da colheita mecânica.

Acontece que as máquinas, especialmente em talhões mais velhos, mostram dificuldade de cortar os colmos de cana rente ao solo, diminuindo sua produtividade agrícola e também a industrial, já que nessa parte a concentração de sacarose tende a ser maior. Outro problema associado ao uso das colhedoras é que elas provocam mais danos mecânicos às gemas da cana, diminuindo o vigor de suas brotações. Ao mesmo tempo, tem-se relatado aumento de problemas fitossanitários, com influência na produção, em decorrência do excesso de palha deixado no campo pela colheita mecânica de cana crua.

Também o crescimento do plantio mecanizado está fazendo com que se utilizem entre $50 \%$ e $100 \%$ a mais de mudas de cana por hectare e sua brotação tem-se revelado menor que o plantio manual, comprometendo a produtividade da lavoura (CONAB, 2013b).

Braga Júnior (2012), a partir de levantamentos do Centro de Tecnologia Canavieira (CTC), informa que tanto o plantio como a colheita mecanizada têm trazido perdas de produtividade por hectare na lavoura canavieira no Centro Sul do Brasil. No caso do plantio, dependendo da variedade de cana usada, as perdas variaram entre 1,3\% e 16,0\%. Já a adoção da colheita mecânica de cana não queimada resultou em perdas de 5\% a 10\%, entre as safras 2006 e 2010, nas usinas denominadas "novatas".

Este é um ponto bastante interessante para o qual se sugere que se realizem levantamento de novas informações e pesquisas de campo. Até que ponto a muito rápida mudança tecnológica canavieira comprometeu os rendimentos por área da lavoura? Está-se em fase de adaptação às novas tecnologias ou os problemas relatados tendem a perdurar? Esses problemas surpreenderam pela sua intensidade e mesmo chegaram a comprometer as aparentes vantagens de custo associadas ao método de colheita mecânica?

\section{3 - A DIMINUIÇÃO NO NÚMERO DE TRABALHADORES CANAVIEIROS}

Os dados de ocupação aqui utilizados são originários do Programa de Disseminação de Estatísticas do Trabalho do Ministério do Trabalho e Emprego (MTE) do Governo Federal do Brasil, que registra informações sobre ocupação formal, prestadas pelas próprias empresas empregadoras ${ }^{9}$.

\footnotetext{
Nas condições prevalecentes no Estado de São Paulo, estimava-se que a ocupação formal representasse pouco mais de $90 \%$ da ocupação total em empresas sucroalcooleiras em 2003 (MORAES, 2004). Atualmente, esse valor deve ser maior, acompanhando a tendência de aumento de formalidade no mercado de trabalho brasileiro como um todo.
} 
As empresas enviam dois tipos de relatório ao MTE, um com dados de ocupação em 31 de dezembro de cada ano, chamado de Relação Anual de Informações Sociais (RAIS). O outro registra, para cada mês, a movimentação (admissão e demissão) das pessoas ocupadas, chamado de Cadastro Geral de Empregados e Desempregados (CAGED). A partir das informações da RAIS de um ano qualquer, pode obter-se uma estimativa do número de pessoas ocupadas em determinado mês do ano seguinte, agregando-se os números de admissões e demissões registrados até então pelo CAGED. Também é possível obter nesses relatórios outros tipos de informação como a composição de gênero e a faixa etária das pessoas ocupadas.

Levantaram-se informações de ocupação, mês a mês, de dezembro de 2006 a dezembro de 2013, de empresas classificadas na RAIS e no CAGED nas seguintes classes: Cultivo da Cana-de-açúcar, Fabricação do Açúcar em Bruto, Fabricação do Açúcar Refinado e Fabricação de Âlcool. É preciso observar que essa classificação se estabelece de acordo com atividade principal que a empresa declara exercer, sendo que uma empresa classificada, por exemplo, como de Cultivo da Cana-de-açúcar, pode se dedicar também a outras atividades agrícolas ou mesmo de outros ramos da economia.

Outra observação é que no Brasil é grande a integração vertical entre produção de açúcar e álcool e produção da cana. Na safra 2010/11 foi constatado que nas agroindústrias sucroalcooleiras do Centro Sul 63,4\% da cana moída eram provenientes de canaviais das próprias usinas ou destilarias e apenas 34,6\% provinham de fornecedores independentes, enquanto para São Paulo esses números eram, respectivamente, 57,2\% e 42,8\% (CONAB, 2013b). Assim, pressupõe-se que o número de pessoas ocupadas em atividades agrícolas nas empresas dedicadas à Fabricação do Açúcar em Bruto, Fabricação do Açúcar Refinado ou Fabricação de Álcool seja significativo, embora menos importante que nas dedicadas ao Cultivo da Cana-de-açúcar.

Para obter-se o número de pessoas ocupadas trabalhou-se com o nível de classificação Família Ocupacional, conforme a Classificação Brasileira de Ocupações $(\mathrm{CBO})^{10}$. Nos quatro tipos de empresas

ACBO foi instituída pela Portaria Ministerial no. 397, em 2002, e tem por finalidade a identificação das ocupações no mercado de trabalho, para fins classificatórios junto a registros administrativos e domiciliares. Ela classifica as ocupações em quatro grupos. OGrande Grupo Ocupacional constitui o nível mais agregado da classificação. O Subgrupo Ocupacional Principal busca melhorar o equilíbrio hierárquico entre o número de grandes grupos e subgrupos. O Subgrupo Ocupacional indica o domínio dos campos profissionais de Famílias Ocupacionais agregadas. E, por fim, a Família Ocupacional contempla 596 grupos de base, que agrupam situações de emprego ou ocupação similares (MTE, 2009). 
sucroalcooleiras foram encontrados registros de 385 famílias ocupacionais, que, de acordo com seus descritores, foram classificadas, inicialmente, em quatro agrupamentos: Pessoas Ocupadas na Agricultura, Pessoas Ocupadas na Indústria, Pessoas Ocupadas em Atividades Administrativas e de Apoio e Pessoas Ocupadas em Atividades não Sucroalcooleiras ${ }^{11}$.

O primeiro grupo, chamado daqui por diante de Pessoas na Agricultura, contém aquelas ocupações diretamente ligadas à lavoura canavieira. O segundo grupo, Pessoas na Indústria daqui para frente, é composto por ocupações vinculadas às atividades das usinas e destilarias. O terceiro grupo, Administrativos e de Apoio daqui para diante, é composto por aquelas ocupações em atividades de escritórios, de manutenção, de copa, limpeza etc. No quarto grupo, pouco expressivo, representando menos que $2 \%$ do total de ocupação em empresas sucroalcooleiras, e que será chamado daqui para frente simplesmente de Ocupadas não Sucroalcooleiras, são registradas as demais ocupações em outras classes de empresas, que não as aqui consideradas.

A seguir subdividiu-se o grupo Pessoas na Agricultura em três subgrupos: Trabalhadores Canavieiros não Qualificados, Trabalhadores da Mecanização Agrícola e Outras Pessoas Ocupadas na Agricultura. O primeiro subgrupo, que se denomina simplesmente de Trabalhadores Canavieiros, resulta da soma de três Famílias Ocupacionais, quais sejam Trabalhadores Agropecuários em Geral, Trabalhadores de Apoio à Agricultura e Trabalhadores Agrícolas na Cultura de Gramíneas e entendese que aí estão incluídos aqueles que se dedicam às atividades que não exigem maior qualificação profissional, como o plantio e o corte de canade-açúcar. $\mathrm{O}$ segundo subgrupo, simplesmente Trabalhadores da Mecanização, constitui uma Família Ocupacional específica da CBO e o terceiro resulta da soma das demais 12 famílias ocupacionais observadas na lavoura canavieira, em posição de chefia ou com maiores exigências de qualificação profissional, e será chamado de Outras Ocupações na Agricultura.

Levando-se em conta que o número de pessoas ocupadas sucroalcooleiras apresenta forte sazonalidade ao longo do ano, especialmente entre os Trabalhadores Canavieiros, optou-se por considerar o número médio de ocupação entre os meses de cada ano entre 2007 e 2013. Adicionalmente,

Para obter maiores detalhes sobre essa distribuição das Famílias Ocupacionais sucroalcooleiras, pode-se consultar Baccarin \& Bara (2009). 
para os Trabalhadores Canavieiros são apresentadas informações da ocupação em todos os meses de 2007 a 2013.

A Tabela 2 mostra que o número médio de pessoas ocupadas no Estado de São Paulo em empresas sucroalcooleiras reduziu-se em 26.639 entre 2007 e 2013, o que em termos relativos resulta em queda de $8,4 \%$. Cresceu o número de Pessoas na Indústria, de Ocupadas não Sucroalcooleiras e, especialmente, de Administrativos e de Apoio. A redução da ocupação concentrou-se nas Pessoas na Agricultura e, neste grupo, nos Trabalhadores Canavieiros. Seu número diminuiu em 84.085 pessoas ou em 47,1\%, entre 2007 e 2013.

Tabela 2 - Pessoas Ocupadas em Empresas Sucroalcooleiras, de Acordo com Grupos e Subgrupos, Estado de São Paulo, média mensal de 2007 a 2013.

\begin{tabular}{lrrrrrrrr}
\hline Grupos e Subgrupos & 2007 & 2008 & 2009 & 2010 & 2011 & 2012 & 2013 & $\begin{array}{c}\text { Variação } \\
2007-13\end{array}$ \\
\hline $\begin{array}{l}\text { 1 - Pessoas na } \\
\text { Agricultura }\end{array}$ & 209.700 & 205.415 & 190.017 & 180.148 & 169.389 & 158.063 & 145.347 & -64.353 \\
$\begin{array}{l}\text { - Trabalhadores } \\
\text { Canavieiros }\end{array}$ & 178.510 & 171.228 & 154.274 & 140.460 & 126.538 & 112.268 & 94.425 & -84.085 \\
$\begin{array}{l}- \text { Trabalhadores da } \\
\text { Mecanização }\end{array}$ & 24.279 & 26.738 & 28.175 & 31.867 & 34.881 & 37.360 & 42.547 & 18.268 \\
$\begin{array}{l}\text { - Outras Ocupações } \\
\text { na Agricultura }\end{array}$ & 6.911 & 7.449 & 7.568 & 7.821 & 7.970 & 8.435 & 8.375 & 1.464 \\
$\begin{array}{l}\text { 2 - Pessoas na } \\
\text { Indústria }\end{array}$ & 40.186 & 41.011 & 44.614 & 46.815 & 46.923 & 48.585 & 47.407 & 7.221 \\
$\begin{array}{l}\text { 3 - Administrativos e } \\
\text { Apoio }\end{array}$ & 61.637 & 67.108 & 69.619 & 76.007 & 79.145 & 87.231 & 91.110 & 29.473 \\
$\begin{array}{l}\text { 4- Ocupadas não } \\
\text { Sucroalcooleiras }\end{array}$ & 4.600 & 5.694 & 6.421 & 7.444 & 3.329 & 5.269 & 5.620 & 1.020 \\
\hline Total & 316.123 & 319.228 & 310.671 & 310.414 & 298.786 & 299.148 & 289.484 & -26.639 \\
\hline
\end{tabular}

Fonte: MTE (2014).

Os impactos da ampliação da mecanização da lavoura canavieira, especialmente em sua colheita, revelaram-se significativos. Assim, os Trabalhadores Canavieiros que representavam $56,5 \%$ do total da ocupação sucroalcooleira em 2007 tiveram sua importância reduzida para 32,6\% em 2013. Dessa forma, o perfil de ocupação nas empresas sucroalcooleiras paulistas tem se alterado, com ganho de participação daquelas ocupações com maiores exigências quanto à qualificação profissional.

Fredo et al (2012), com base na evolução da porcentagem de área colhida mecanicamente e considerando-se que se trabalhe efetivamente 132 dias durante a safra canavieira e uma produtividade média de 8,9 toneladas de cana colhidas por homem/dia, estimam que o contingente de cortadores de cana tenha passado de 210 mil em 2007 para 104 mil em 2011 em São 
Paulo, queda de mais de 50\%. Essa redução mais intensa que a apresentada na Tabela 2 encontra uma provável explicação no fato de esses autores consideram apenas os cortadores de cana, enquanto nos Trabalhadores Canavieiros estão incluídas pessoas que se dedicam a outras operações, além do corte de cana-de-açúcar.

A Tabela 3 revela como varia o número de Trabalhadores Canavieiros ao longo dos meses de cada ano. As contratações se acentuam a partir de fevereiro e o número máximo desses trabalhadores vai ser registrado nos meses de maio e junho de cada ano. A partir daí há uma redução gradativa, com as demissões superando as admissões, o que se acentua no mês de dezembro, em que se constata o menor patamar de contratação dos Trabalhadores Canavieiros.

Tabela 3 - Número de Trabalhadores Canavieiros em Empresas Sucroalcooleiras do Estado de São Paulo nos meses de 2007 a 2013.

\begin{tabular}{lllrrrrr}
\hline \multicolumn{1}{c}{ Mês } & \multicolumn{1}{c}{2007} & \multicolumn{1}{c}{2008} & \multicolumn{1}{c}{2009} & \multicolumn{1}{c}{2010} & \multicolumn{1}{c}{2011} & \multicolumn{1}{c}{2012} & \multicolumn{1}{c}{2013} \\
\hline Janeiro & 121.183 & 107.202 & 95.233 & 95.116 & 90.325 & 82.069 & 75.654 \\
Fevereiro & 147.704 & 133.831 & 105.931 & 110.278 & 104.387 & 96.657 & 84.704 \\
Março & 165.461 & 152.807 & 143.142 & 142.949 & 120.155 & 106.299 & 93.437 \\
Abril & 194.655 & 195.870 & 178.593 & 162.205 & 143.413 & 116.791 & 106.381 \\
Maio & 213.753 & 206.723 & 185.718 & 166.408 & 152.967 & 130.182 & 109.479 \\
Junho & 212.966 & 205.495 & 182.735 & 165.807 & 153.333 & 129.130 & 107.908 \\
Julho & 207.111 & 200.672 & 177.824 & 163.272 & 151.247 & 128.095 & 104.014 \\
Agosto & 205.150 & 195.828 & 174.575 & 160.055 & 147.382 & 125.370 & 100.689 \\
Setembro & 203.919 & 192.324 & 173.115 & 156.094 & 143.567 & 123.719 & 98.464 \\
Outubro & 198.658 & 189.571 & 171.678 & 148.630 & 126.773 & 121.639 & 96.443 \\
Novembro & 175.630 & 179.094 & 168.439 & 126.082 & 100.331 & 112.306 & 89.878 \\
Dezembro & 95.930 & 95.323 & 94.309 & 88.618 & 84.576 & 74.957 & 66.053 \\
\hline
\end{tabular}

Fonte: MTE (2014).

Tomando-se dezembro e janeiro como meses típicos de entressafra, percebe-se que o número de Canavieiros apresentou redução entre 2007 e 2013 , de $31,1 \%$ em dezembro e de $37,6 \%$ em janeiro. Isso porque as operações nessa fase, com destaque para o plantio, estão aumentando seu nível de mecanização.

Já no período da safra os efeitos da mecanização da colheita são relativamente mais fortes. Dessa forma, entre 2007 e 2013, o número de Canavieiros caiu $48,8 \%$ no mês de maio e $49,3 \%$ no mês de junho, revelando instabilidade ainda maior de emprego nesse período quando comparado com a entressafra. 
Pelo Gráfico 1 pode se perceber que houve uma redução no grau de sazonalidade de contratação de Trabalhadores Canavieiros. Em 2007 a contratação no mês de maio superou em $123 \%$ aquela observada em dezembro. Tal valor caiu para $88 \%$ em 2010 e para $66 \%$ em 2013 , quase a metade da de 2007.

Gráfico 1 - Índice Mensal do número de Trabalhadores Canavieiros em Empresas Sucroalcooleiras de São Paulo, meses de 2007, 2010 e 2013. TENDO DEZEMBRO COMO BASE (100).

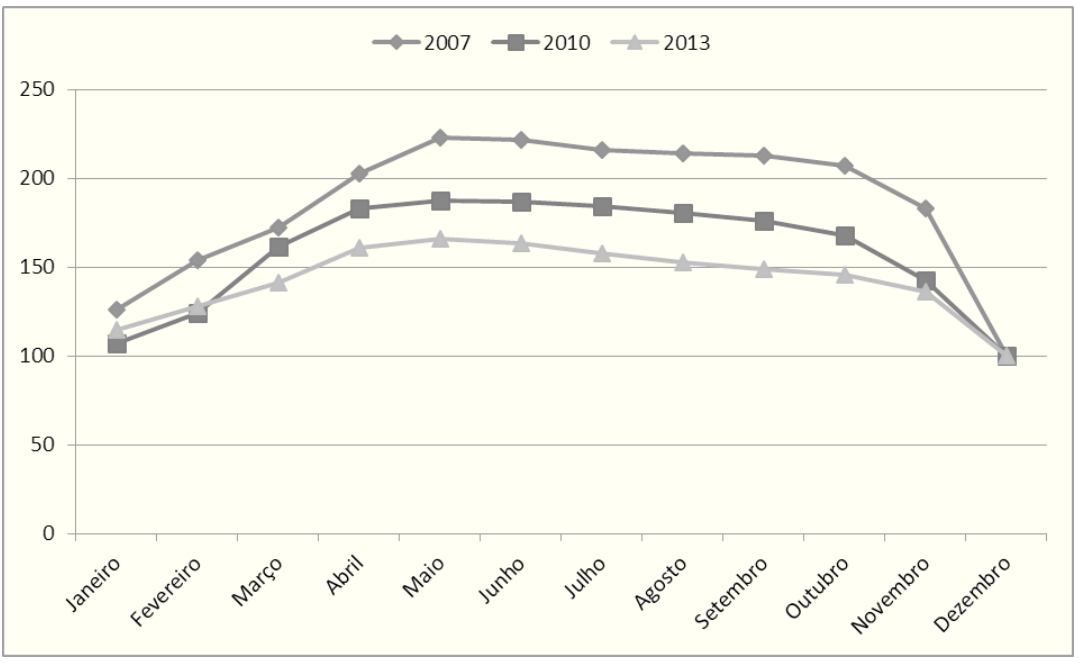

Fonte: MTE (2014).

Essa queda da sazonalidade, acompanhada da redução para um pouco menos da metade do número de Trabalhadores Canavieiros entre maio de 2007 e de 2013 (vide Tabela 3), tem feito com que se diminua a presença de migrantes sazonais, oriundos especialmente do norte de Minas Gerais e de estados da Região Nordeste, no corte de cana em São Paulo. Uma evidência indireta disso foi o fechamento em 2014 da representação da Comissão Pastoral dos Migrantes no município de Guariba (SP), depois de mais de duas décadas de atuação local.

Pode-se também levantar algumas questões, ainda que preliminarmente, sobre os Trabalhadores Canavieiros dispensados e que ficam no próprio Estado de São Paulo, tais como, qual a relevância desse fato, quais os destinos desses trabalhadores, que ações públicas são ou poderiam ser feitas? 
Dados de pesquisa coordenada por Baccarin (2012) indicam que em 2009 os Trabalhadores Canavieiros representavam 1,5\% no mês de junho e $0,8 \%$ no mês de dezembro do total de ocupação formal no Estado de São Paulo. Ainda que no Estado tal participação possa ser considerada pequena, em alguns municípios ela se mostrava muito alta. A mesma pesquisa aponta que em muitos municípios paulistas os Trabalhadores Canavieiros representavam mais de 5\% da ocupação local e em 68 deles (em que se concentravam $57 \%$ desses trabalhadores) essa importância superava 10\% na entressafra e $20 \%$ na safra. Nesses casos, a desocupação dos Canavieiros, em não havendo outras opções de ocupação, tende a se transformar em um problema social bastante relevante.

Alguns poucos Trabalhadores Canavieiros, após capacitação profissional, conseguem ser absorvidos em outras atividades nas próprias empresas sucroalcooleiras, especialmente como operadores de máquinas. Contudo, essa possibilidade apresenta forte barreira para muitos, em decorrência de ausência de qualificação profissional e do baixo nível de escolaridade $^{12}$, mesmo porque as atividades administrativas e de apoio sucroalcooleiras, que mostraram forte expansão entre 2007 e 2013 (vide Tabela 2), tendem a exigir nível médio ou superior de ensino.

Outras informações da pesquisa acima citada foram obtidas em 2011 através de entrevistas com sindicalistas e gestores municipais em 26 pequenas cidades canavieiras próximas a Ribeirão Preto (SP). Foi reportada a diminuição expressiva do número de migrantes que se deslocam para o corte de cana, resultando em efeitos negativos no comércio local e menor pressão sobre serviços públicos, de educação (creche, em especial) e saúde, por exemplo. Foi apontada, com destaque, a construção civil e, secundariamente, o setor terciário, especialmente comércio e serviços domésticos, como principais destinos dos que estão deixando o corte de cana-de-açúcar. As ações de requalificação e recolocação profissional, embora existentes em vários municípios, não apresentavam nenhum ponto especificamente direcionado para os Canavieiros, mesmo porque a posição predominante entre os entrevistados era a de que a maior parte dos trabalhadores dispensados do corte da cana estava conseguindo colocação em outros setores, sem maiores dificuldades. Em algumas cidades, entretanto, a percepção era de que a mecanização canavieira acarretou graves problemas sociais. (BACCARIN, 2012).

\footnotetext{
Baccarin et al (2011) mostram que 74,6\% dos Trabalhadores Canavieiros em São Paulo, registrados em dezembro de 2008, não tinham completado o Ensino Fundamental.
} 
4 - MUDANÇAS NA COMPOSIÇÃO DE GÊNERO E NA FAIXA ETÁRIA DOS CANAVIEIROS

A partir da diminuição do número de Trabalhadores Canavieiros e do aumento da quantidade média diária de cana por eles cortada, seria possível supor, em um primeiro instante, que as empresas sucroalcooleiras tentariam manter em seus quadros os trabalhadores mais jovens e do sexo masculino, com maior vigor físico. Entretanto, deve-se considerar também que o corte de cana manual é muito desgastante, fazendo com que aqueles que consigam maior escolaridade e formação profissional tendam a se dirigir a outras ocupações com melhores condições de trabalho. Ficariam no corte de cana e em suas outras operações manuais aqueles extratos sociais com maiores dificuldade de inserção em outros ramos e atividades econômicas.

Nessa seção, estuda-se como vem evoluindo a participação de mulheres e de jovens entre os Trabalhadores Canavieiros, no período de aceleração da colheita mecânica, usando-se, como na seção anterior, dados da RAIS e do CAGED.

Quanto à presença das mulheres no mercado de trabalho no Brasil, alguns estudos mostram que a sua taxa de participação (divisão da População Economicamente Ativa pela População em Idade Adulta feminina) que vinha se expandindo desde o início dos anos 1990, apresentou leve redução nos últimos anos, embora, neste caso, o número de observações seja pequeno para se afirmar uma nova tendência. Nesse sentido, Barbosa (2014) calcula que, nacionalmente, a taxa de participação de mulheres elevou-se de 52,5\% em 1992 para 63,0\% em 2009 e, a partir de então, apresentou leve queda, alcançando $61,0 \%$ em 2012. Aquele crescimento nacional também aparece em estudo de Fontoura e Gonzalez (2009), enquanto o decréscimo é apontado em boletim SEADE/DIEESE (2014), especificamente para a Região Metropolitana de São Paulo.

As mulheres convivem com piores condições de trabalho. Seu nível de desocupação até 2008 situava-se em $4 \%$ a $6 \%$ pontos percentuais acima da desocupação masculina, embora haja evidência de que nos últimos anos essa diferença tenha caído para 2\% a 3\% (QUINTSLR, 2008; SEADE/ DIEESE, 2014). A análise de Quintslr (2008), para as regiões metropolitanas brasileiras, também aponta que o nível de formalização entre as mulheres era de $40 \%$, contra $50 \%$ dos homens, e seu rendimento médio correspondia a $71,3 \%$ daquele dos homens.

$\mathrm{Na}$ Tabela 4 evidencia-se que o número de homens e mulheres diminuiu, na safra e na entressafra canavieira, sendo que na safra e entre os 
homens a diminuição relativa foi maior. A queda relativamente maior na safra, como já visto, é explicada pelo avanço do processo de colheita mecânica.

TABELA 4 - NúMERO DE HOMENS E MULHERES ENTRE OS T rabalhadores Canavieiros no Estado de São Paulo, da ENTRESSAFRA DE 2006 À SAFRA DE 2014.

\begin{tabular}{|c|c|c|c|c|}
\hline \multirow{2}{*}{ Ano } & \multicolumn{2}{|c|}{ Safra (junho) } & \multicolumn{2}{|c|}{ Entressafra (dezembro) } \\
\hline & Masculino & Feminino & Masculino & Feminino \\
\hline 2006 & - & - & 80.553 & 14.238 \\
\hline 2007 & 187.595 & 25.371 & 78.079 & 14.054 \\
\hline 2008 & 180.824 & 24.671 & 76.383 & 15.761 \\
\hline 2009 & 160.014 & 22.721 & 77.165 & 15.837 \\
\hline 2010 & 143.432 & 22.375 & 69.353 & 15.470 \\
\hline 2011 & 131.020 & 22.313 & 61.248 & 14.988 \\
\hline 2012 & 109.590 & 23.984 & 56.355 & 13.984 \\
\hline 2013 & 90.854 & 17.054 & 53.508 & 12.545 \\
\hline 2014 & 72.608 & 13.668 & - & - \\
\hline Variação Absoluta & -114.987 & -11.703 & -27.045 & -1.693 \\
\hline Variação Relativa & $-61,3$ & $-46,1$ & $-33,6$ & $-11,9$ \\
\hline
\end{tabular}

Fonte: MTE, 2014.

Quanto ao menor impacto relativo sofrido pelas mulheres, isso é mais nítido na entressafra, em que se registram aqueles trabalhadores com vínculo de emprego com menos de instabilidade do que na safra. Uma provável explicação é que os homens estariam conseguindo mais facilmente alcançar postos de trabalhos em outros ramos, com atividades menos desgastantes e mais bem remuneradas.

O Gráfico 2 revela que no conjunto das ocupações sucroalcooleiras, em que aquelas com maior exigência de qualificação profissional vêm ganhando importância, a participação das mulheres praticamente não se alterou no período todo e é extremamente minoritária, próxima a 10\% do total de ocupação.

Por sua vez, entre os Trabalhadores Canavieiros, a participação feminina cresceu até 2012, tanto na safra quanto na entressafra, revelandose bem maior que sua participação no conjunto sucroalcooleiro. Mais uma evidência das maiores dificuldades das mulheres, pelo menos aquelas com baixo nível de escolaridade, conseguirem alcançar empregos com melhores condições de trabalho.

A queda da participação das mulheres entre os Canavieiros a partir de 2013 poderia estar relacionada com a diminuição, nos últimos anos, da taxa de participação das mulheres no mercado de trabalho nacional, já 
relatada. Mas, julga-se que ainda é cedo para ter maior segurança nessa informação, posto que baseada em pequeno número de observações. Além disso, a taxa nacional de participação dos homens também diminuiu pós 2009, em intensidade semelhante ao das mulheres (BARBOSA, 2014).

Em relação aos jovens, um fenômeno mundialmente constatado é sua maior taxa de desocupação em relação a faixas populacionais mais velhas. Não é diferente no Brasil, sendo que na PNAD de 2011 se constatou que a desocupação entre as pessoas de 15 a 24 anos era de $16,3 \%$, contra $5,7 \%$ nas pessoas de 25 a 49 anos e de $2,8 \%$ nas pessoas com 50 anos ou mais (GUIMARÃES \& ALMEIDA, 2013).

Gráfico 2 - ParticipaÇão PORCENTUAL de MUlHERES nOS TRABALHADORES Canavieiros e no Total de Ocupação Sucroalcooleira, Estado de São Paulo, DEZEMBRO DE 2006 A JUNHO 2014.

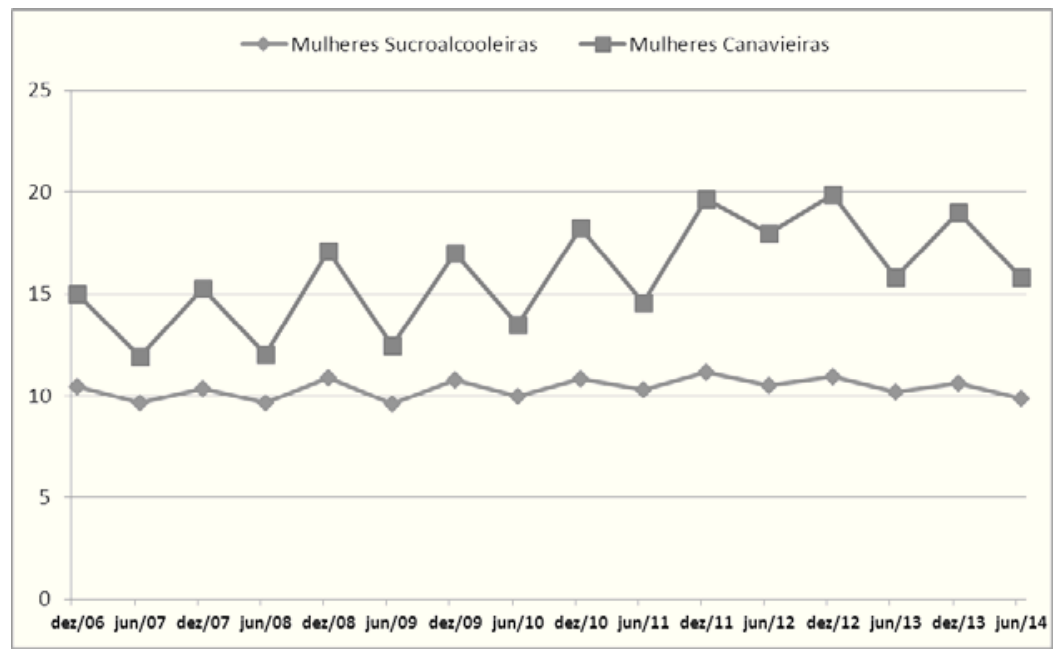

Fonte: MTE, 2014.

Esses autores mostram que a taxa de participação dos jovens, que era de $57,7 \%$ em 2001, apresentou crescimento até 2005, ultrapassando $60 \%$, e depois caiu, atingindo 53,6\% em 2011. Nos anos mais recentes essa taxa de participação continuou caindo, mais acentuadamente do que o constatado entre os mais velhos (IPEA, 2014). Uma provável explicação seria o aumento da dificuldade dos jovens em entrarem no mercado de trabalho, outra explicação seria o adiamento deliberado dessa entrada diante 
da melhoria das condições de vida das famílias brasileiras e das maiores possibilidade de se continuar estudando ${ }^{13}$. Nesse caso, a maior disponibilidade do Fundo de Financiamento Estudantil (Fies), cujas matrículas passaram de 76 mil em 2010 para 556 mil em 2013, seria um fato adicional a contribuir para a entrada mais tardia de jovens no mercado de trabalho (IPEA, 2014).

A Tabela 5 revela que houve grande diminuição da participação dos jovens até 24 anos entre os Canavieiros, especialmente no período da safra. A faixa intermediária, de trabalhadores entre 25 e 49 anos, apresentou leve aumento de participação na safra, pelo menos até 2013 , e uma tendência de queda na entressafra. Chama mesmo a atenção o aumento da participação dos trabalhadores acima de 50 anos, que mais do dobrou no período da safra e aumentou em $60 \%$ na entressafra ${ }^{14}$.

Tabela 5 - Participação porcentual de diferentes faixas etárias de Trabalhadores Canavieiros, Estado de São Paulo, dezembro de 2006 a junho de 2014.

\begin{tabular}{rrrrrrr}
\hline \multirow{2}{*}{ Ano } & \multicolumn{2}{c}{ Safra (Junho) } & \multicolumn{4}{c}{ Entressafra (Dezembro) } \\
& menos 24 anos & 25 a 49 anos & mais 50 anos & menos 24 anos & 25 a 49 anos & mais 50 anos \\
\hline 2006 & - & - & - & 21,8 & 65,2 & 13,0 \\
2007 & 31,0 & 60,9 & 8,1 & 19,8 & 65,7 & 14,5 \\
2008 & 30,2 & 61,1 & 8,7 & 18,3 & 65,8 & 16,0 \\
2009 & 28,4 & 61,9 & 9,7 & 18,1 & 65,3 & 16,6 \\
2010 & 26,5 & 62,5 & 10,9 & 16,6 & 65,0 & 18,4 \\
2011 & 25,4 & 62,4 & 12,1 & 15,2 & 64,4 & 20,4 \\
2012 & 23,2 & 62,6 & 14,2 & 15,2 & 62,5 & 22,3 \\
2013 & 21,6 & 62,3 & 16,1 & 19,2 & 60,0 & 20,8 \\
2014 & 23,0 & 60,1 & 16,9 & - & - & - \\
\hline
\end{tabular}

Fonte: MTE, 2014.

Além de questões mais gerais, ligadas às condições do mercado de trabalho no Brasil, a evidência de que os jovens estão deixando mais celeremente as atividades canavieiras, pode apontar para o fato de que eles

3 “A explicação para esse movimento pode, (...), estar atrelada a alguma forma de desalento. $\mathrm{O}$ arrefecimento no ritmo de criação de vagas e a percepção de que a pouca experiência restringe ainda mais as chances de obter uma colocação podem fazer com que esses jovens desistam de procurar emprego e se retirem do mercado de trabalho. Uma segunda explicação (...) pode estar relacionada a uma melhora na redistribuição de renda no país. A incorporação de reajustes reais nos salários, ao longo dos últimos anos, aliada à expansão do número de beneficiados pelos programas sociais governamentais, vem gerando um crescimento da renda domiciliar, de modo que estes jovens podem sair do mercado de trabalho para, entre outros propósitos, voltar a estudar." (IPEA, 2014,. Pg. 34).

14 Para efeito comparativo, a participação de pessoas com mais de 50 anos aumentou também no Total de Ocupação Sucroalcooleira, mas menos intensamente. Assim, entre a safra de 2007 e 2014, essa participação passou de 8,9\% a 14,6\% e entre a entressafra de 2006 e a de 2013 , de $12,3 \%$ para $17,8 \%$ (MTE, 2014). 
estão conseguindo, ao contrário dos Canavieiros mais velhos, oportunidades em ocupações que ofereçam melhores condições de trabalho, entre outros motivos, por contarem com maior escolaridade, ou mesmo que estão prolongando seus anos de estudo sem trabalharem ao mesmo tempo.

O Gráfico 3 mostra a evolução da idade média das pessoas ocupadas em empresas sucroalcooleiras. Foi construído a partir de uma média ponderada que levou em conta o número de pessoas em cada uma das faixas etárias consideradas na RAIS e no CAGED ${ }^{15}$. Há um leve crescimento da idade média do Total de Ocupação Sucroalcooleira, bem como dos Trabalhadores Canavieiros. Em cada ano, a idade média cai no período da safra, de maneira um pouco mais acentuada entre os Canavieiros. Uma provável explicação é que nessa fase parte considerável das ocupações tem caráter temporário, ou seja, é mais precária, conseguindo arregimentar mais os indivíduos daquelas frações sociais com maior taxa de desocupação, como os mais jovens.

Gráfico 3 - Idade média em anos do Total de Pessoas Ocupadas Sucroalcooleiras e dos Trabalhadores Canavieiros, Estado de São Paulo, DEZEMBRO DE 2006 A JUNHO DE 2014.

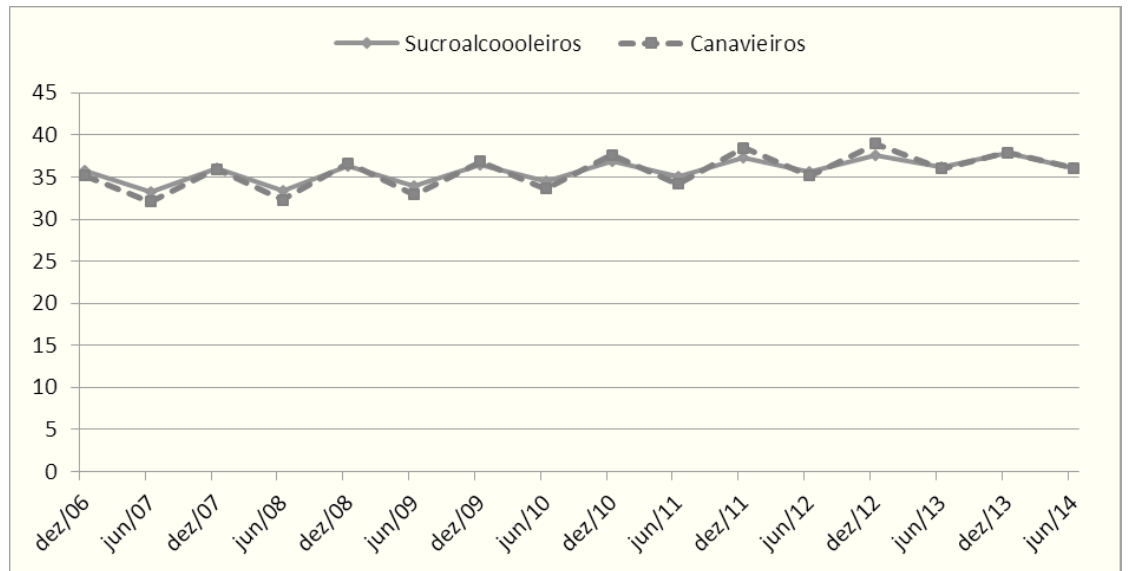

Fonte: MTE, 2014.

\footnotetext{
As faixas etárias disponíveis nas publicações da RAIS e do CAGED são em número maior que as apresentadas na Tabela 5 desse artigo, quais sejam: até 17 anos, 18 a 24 anos, 25 a 29 anos, 30 a 39 anos, 40 a 49 anos, 50 a 64 anos, 65 anos ou mais. A partir delas é que se procedeu o cálculo da idade média sucroalcooleira e canavieira.
} 


\section{5 - CONSIDERAÇÕES FINAIS}

Há uma questão mais geral associada ao aprofundamento da mecanização canavieira que diz respeito ao controle empresarial sobre o processo produtivo e o ritmo de trabalho. No início do Século XXI, o predomínio da colheita e do plantio manual não inibia que esse controle se desse. No caso da colheita isso era feito com o pagamento dos trabalhadores por produção, incentivando-os a trabalhar até o limite de suas forças físicas. No caso do plantio, o fato da abertura e do fechamento dos sulcos serem mecânicos, ditava o ritmo das operações intermediárias, a arrumação e o picamento dos colmos de cana, que eram feitas manualmente.

Contudo, com o plantio totalmente mecanizado e a generalização do corte mecânico de cana o controle sobre o ritmo de trabalho elevou-se. Por exemplo, as colhedoras dispõem de GPS (Global Positioning System) e outros equipamentos informacionais permitindo que todas as suas operações sejam acompanhadas, imediatamente, dos escritórios das empresas.

Ao que parece, a decisão de se ampliar a mecanização do corte de cana foi influenciada pela perspectiva de se ampliar o mercado externo de etanol, que poderia ser prejudicada pela manutenção da queimada associada ao corte manual, à qual se imporia barreira não tarifária. Também foi estimulada, assim como a mecanização do plantio, por estudos preliminares e entendimento de que, com isso, os custos de produção seriam reduzidos.

$\mathrm{Na}$ prática tem se observado que a muito rápida ampliação da área plantada e colhida mecanicamente contribuiu para a queda na produção por hectare dos canaviais em São Paulo pós 2007. Isso não necessariamente significa redução de rentabilidade em relação aos processos manuais, mas talvez tenha sido maior do que os empresários pudessem imaginar, dificultando, inclusive, a obtenção de receitas suficientes para amortizar os investimentos na aquisição do caro maquinário, especialmente para a colheita.

É possível se supor que o nível de desenvolvimento tecnológico no período aqui analisado foi insuficiente para que as máquinas se mostrassem mais eficientes, em termos de produção obtida, do que os Trabalhadores Canavieiros. Evidente, que tal fato pode ser alterado nos próximos anos, sugerindo seu acompanhamento por novas pesquisas e evidências.

Outro fato a ser destacado na adoção da colheita mecânica de cana crua é que ela foi influenciada por mobilizações sociais contrárias à prática da queimada da palha da cultura. Se a decisão fosse apenas vinculada aos interesses empresariais e avaliações de custos, talvez se observasse uma 
importância ainda maior da colheita mecânica de cana queimada, ainda presente em não desprezíveis $10 \%$ da área colhida do Centro Sul.

Os efeitos da mecanização foram muito intensos sobre os Trabalhadores Canavieiros. Enquanto as outras categorias ocupacionais das empresas sucroalcooleiras tiveram seu contingente de pessoas se ampliando entre 2007 e 2013, o número de Canavieiros reduziu-se para quase a metade no Estado de São Paulo. Houve também uma redução para praticamente à metade na sazonalidade no ano da ocupação desses trabalhadores, embora em 2013 ela continuasse ainda muito alta.

O número de Canavieiros dispensados se revela pouco expressivo em relação ao contingente total de ocupados no Estado de São Paulo. Porém, para as regiões canavieiras e para municípios pequenos e com forte dependência da atividade sucroalcooleira aquele número tende a apresentar forte abrangência.

O fato da pessoa deixar de ser cortadora de cana, dada a penosidade desse serviço, pode representar um ganho social, na medida em que se consiga alcançar ocupação menos desgastante e com melhor condição de trabalho. Há nessa passagem a possibilidade de se adotarem políticas públicas mais efetivas, especialmente nos campos de requalificação e recolocação profissional.

Para os que continuam no serviço de corte manual de cana seria importante que se adotassem medidas, como o aumento da quantidade e da duração de intervalos na lide diária e na forma de pagamento, diminuindo o seu desgaste físico.

No período aqui estudado, os Trabalhadores Canavieiros ficaram, na média, mais velhos e a presença relativa de mulheres entre eles aumentou. A indicação é que os jovens, obtendo relativamente maior escolaridade e formação profissional que os mais velhos, procuram, ao longo dos anos, dirigir-se a outras ocupações, evitando os serviços na lavoura canavieira. $\mathrm{Na}$ fase da colheita, porém, a maior necessidade temporária de trabalhadores é resolvida com a contratação de pessoas de frações sociais que convivem com maiores taxas de desocupação, entre eles os mais jovens. Dessa forma, em um mesmo ano, a idade média dos Canavieiros é mais baixa na safra do que na entressafra.

Por sua vez, as mulheres, em especial aquelas com baixo nível de escolaridade, sofrendo maiores discriminações no mercado de trabalho, acabam por ter menores opções, permanecendo relativamente mais nas atividades canavieiras. 


\section{REFERÊNCIAS BIBLIOGRÁFICAS}

ALVES, Francisco José. da Costa. Migração de trabalhadores rurais do Maranhão e do Piauí para o corte de cana em São Paulo: será este um fenômeno casual ou recorrente da estratégia empresarial do complexo agroindustrial canavieiro? In: NOVAES, José Roberto; ALVES, Francisco José da Costa (Org.). Migrantes: trabalho e trabalhadores no complexo agroindustrial canavieiro (Os Heróis do Agronegócio Brasileiro). São Carlos: EDUFSCAR, 2007. p. 21-54.

ALESP (Assembleia Legislativa do Estado de São Paulo). Texto da Lei n. 11.241, de 19 de setembro de 2002. Disponível em: www.al.sp.gov.br. Acesso em março de 2012.

BACCARIN, José Giacomo. (Coord.). Redução do número de Trabalhadores Rurais Canavieiros não Especializados no Estado de São Paulo: situação nos municípios canavieiros e políticas adotadas. Relatório de Pesquisa, Jaboticabal: FAPESP/SP, 2012.

BACCARIN, José Giacomo; BARA, Janaína Gagliardi. Boletim Ocupação Formal Sucroalcooleira em São Paulo. Número 7 Anexo, outubro de 2009. Disponível em www.fcav.unesp.br/baccarin. Acesso em: 28/ $11 / 2014$.

BACCARIN, José Giacomo et al. Uso da área nos estabelecimentos agropecuários face à expansão da agroindústria canavieira no Estado de São Paulo, de 1990 a 2010. In: 52 . Congresso da Sociedade Brasileira de Economia, Administração e Sociologia Rural, 2014, Goiânia (GO). Anais... Brasília: SOBER, 2014. 1 CD-ROM.

BACCARIN, José Giacomo; GEBARA, José Jorge. Intensificación del ritmo y reducción de los puestos de trabajo de los trabajadores cañeros en el Estado de São Paulo, Brasil. In VI Congreso de la Asociación Latinoamericana de Sociología del Trabajo (ALAST). 2010, Cidade do México (México), Anais... Cidade do México: ALAST, 2010.

BACCARIN, José Giacomo et al. Redução dos Trabalhadores Canavieiros não Qualificados no Estado de São Paulo: situação nos municípios, caracterização social dos trabalhadores e Políticas Públicas adotadas. In: $49^{\circ}$. Congresso da Sociedade Brasileira de Economia, Administração e Sociologia Rural. 2014, Belo Horizonte (MG). Anais... Brasília: SOBER, 2011. 1 CD-ROM.

BARBOSA, Ana Luiza Neves de Holanda. Participação feminina no mercado de trabalho brasileiro. Boletim Mercado de Trabalho - Conjuntura e Análise. Brasília: IPEA/MTE. Número 57, agosto 2014. Disponivel em: http://www.ipea.gov.br/portal/index.php?option $=$ com_content\&view=article\&id $=23659$ \& Itemid=9. Acesso em: 28/11/2014.

BONSUCRO. Disponível em www.bonsucro.com. Acesso em fevereiro de 2013.

BRAGA JÚNIOR, Rubens Leite do Canto. A renovação ocorrida na safra 2012/13 foi satisfatória? In: Seminário Desafios para o aumento da produção brasileira de cana-de-açúcar: uma avaliação do Programa BNDES PRORENOVA. Rio de Janeiro: BNDES, 32 p, 2012.

CONAB (Companhia Nacional de Abastecimento). Safras - Grãos. Séries históricas. Disponível em www.conab.gov.br. Acesso em julho de 2013.

CONAB (Companhia Nacional de Abastecimento). Safras - Cana-de-açúcar. Séries históricas. Disponível em www.conab.gov.br. Acesso em julho de 2013a.

CONAB (Companhia Nacional de Abastecimento). Perfil do setor de açúcar e álcool no Brasil - safra 2010/11. Brasília: CONAB, 2013b. 64 p.

FONTOURA, Natália de Oliveira; GONZALEZ, Roberto. Aumento da participação de mulheres no mercado de trabalho: mudança ou reprodução da desigualdade. Boletim Mercado de Trabalho - Conjuntura e Análise. Brasília: IPEA/MTE. Número 41, novembro 2009. Disponível em: http://www.ipea.gov.br/ portal/index.php?option $=$ com_content\&view 
$=$ article\&id $=5744 \&$ Itemid $=9$. Acesso em: 28/11/2014.

FREDO, Carlos Eduardo et al. Índice de mecanização na colheita da cana-de-açúcar no estado de São Paulo e nas regiões produtoras paulistas, junho de 2007. Disponível em http://www.iea.sp.gov.br/out/ verTexto.php? codTexto=9240. Acesso em março de 2008.

FREDO, Carlos Eduardo et al. Cana-de-açúcar - efeitos da mecanização nos empregos. In: Agroanalysis. São Paulo: FGV, vol. 32, no. 4, p. 24 e 25, abril 2012.

GONÇALVES, José Sidnei; SOUZA. Sueli Alves Moreira. Proibição da queima de cana no Estado de São Paulo: simulações dos efeitos na área cultivada e na demanda pela força de trabalho. Informações Econômicas, São Paulo, v. 28, n. 3, p. 21-34, março 1998.

GUIMARÃES, Alexandre Queiroz; ALMEIDA, Mariana Eugenio. Os jovens e o mercado de trabalho: evolução e desafios da política de emprego no Brasil. Temas de Administração Pública (UNESP. Araraquara), v. 8, n. 2, 2013. Disponível em: http://seer.fclar.unesp.br/temasadm/article/view/6845/4926. Acesso em: $28 / 11 / 2014$.

IBGE (Instituto Brasileiro de Geografia e Estatística). Censo Agropecuário 2006. Rio de Janeiro: IBGE, 2009. $777 \mathrm{p}$.

IBGE (Instituto Brasileiro de Geografia e Estatística). Produção Pecuária Municipal. Rio de Janeiro: IBGE. 2013.

IBGE (Instituto Brasileiro de Geografia e Estatística). Sistema IBGE de Recuperação Automática Pesquisa Nacional por Amostra de Domicílios: Síntese de Indicadores (Tabelas - Trabalho). Disponível em: www.sidra.ibge.gov.br/pnad/pnadpb.asp?0 $=3 \& \mathrm{i}=\mathrm{P}$. Acesso em novembro 2014.

IDEA (Instituto Desenvolvimento Agroindustrial). Indicadores de desempenho da agroindústria canavieira - safras 2010/11 e 2011/12. Ribeirão Preto (SP): Grupo IDEA, 2012. 98 p.

IEA (Instituto de Economia Agrícola). Banco de dados. Disponível em www.iea.sp.gov.br. Acesso em março de 2012.

IEA (Instituto de Economia Agrícola). Banco de dados. Disponível em www.iea.sp.gov.br. Acesso em novembro de 2014.

INPE (Instituto Nacional de Pesquisas Espaciais). Monitoramento da cana-de-açúcar - via imagens de satélite. Disponível em www.dsr.inpe.br/mapdsr. Acesso em março de 2013.

IPEA (Instituto de Pesquisa Econômica Aplicada). Mercado de Trabalho. Carta de Conjuntura. Brasília: IPEA, março de 2014.

LIMA, João Ricardo Ferreira de. Tabulação especial dos dados da Pesquisa Nacional por Amostra de Domicílio. Comunicação pessoal. 2014.

MTE (Ministério do Trabalho e Emprego). Classificação Brasileira de Ocupações. Disponível em www.mtecbo.gov.br. Acesso em novembro de 2009.

MTE (Ministério do Trabalho e Emprego). Programa de Disseminação de Estatística do Trabalho. Disponível em www.mte.gov.br. Acesso em outubro de 2014.

MORAES, Márcia Azanha Ferraz Dias de. Mercado de trabalho do setor de açúcar e álcool: desafios atuais e perspectivas futuras. Workshop Mercado de Trabalho do Setor Sucroalcooleiro, Desafios e Perspectivas Futuras, 2003, Piracicaba. Piracicaba: ESALQ/USP, 2004, 11 p.

OLIVEIRA, Ana Maria Soares de. Perspectivas sobre o setor sucroalcooleiro frente à redução da queimada de cana-de-açúcar, a intensificação do corte mecanizado e a certificação socioambiental. Presidente Prudente, 1999. 7 p. Disponível em: http://www.agencia.cnptia.embrapa.br/Repositorio/ Perspectivas_setor_sucoalcooleiro_000fjablj0y02wyiv809gkz51gf7ldgy.pdf. Acesso em: 28/11/2014.

OLIVEIRA, Marli Dias Mascarenhas; NACHILUK, Katia. Custo de produção de cana-de-açúcar nos 
diferentes sistemas de produção nas regiões do Estado de São Paulo. Informações Econômicas, São Paulo, v. 41, n. 1, p. 5 - 33, janeiro 2011. Disponível em: http://www.iea.sp.gov.br/out/ LerTexto.php? codTexto=12045. Acesso em: 28/11/2014.

PAES, Luiz Antônio Dias. Áreas de expansão do cultivo da cana. In: MACEDO, Isaias. de C. (Org.). A energia da cana-de-açúcar - doze estudos sobre a agroindústria da cana-de-açúcar no Brasil e sua sustentabilidade. São Paulo: ÚNICA, 2007. P. 125-133. (2 $2^{\mathrm{a}}$. Edição).

QUINTSLR, Márcia Maria Melo (Coordenadora). Algumas características da inserção das mulheres no mercado de trabalho - Recife, Salvador, Belo Horizonte, Rio de Janeiro, São Paulo e Porto Alegre 2003. 2008. Pesquisa Mensal de Emprego. Rio de Janeiro: IBGE, 2008. Disponível em: http://www.ibge.gov.br/ home/estatistica/indicadores/trabalhoerendimento/pme mulher/Suplemento Mulher 2008.pdf. Acesso em: 28/11/2014.

RAMOS, Pedro. O futuro da ocupação na agroindústria canavieira do Brasil: uma discussão dos trabalhos disponíveis e um exercício de estimação. Informações Econômicas, São Paulo, n. 37, v. 11, p. 69-75, novembro de 2007.

SEMA/SP (Secretaria de Meio Ambiente do Governo do Estado de São Paulo). Etanol verde - fechamento safra 2012-13. Disponível em www.ambiente.sp.gov.br. Acesso em junho 2013.

SILVA, Maria Aparecida Moraes. Trabalho e trabalhadores na região do mar de cana e do rio de álcool. Agrária, São Paulo, v. 2, n. 1, p. 2-39, 2005. Disponível em: http://www.revistas.usp.br/agraria/article/ view/103. Acesso em: 28/11/2014.

SEADE (Fundação Sistema Estadual de Análise de Dados); DIEESE (Departamento Intersindical de Estatística e Estudos Socioeconômicos). A presença feminina no mercado de trabalho em 2013 na Região Metropolitana de São Paulo. Mulher e Trabalho. São Paulo: SEADE/DIEESE. Número 25, março de 2014.

UNICA (União da Indústria de Cana-de-Açúcar). Revisão de safra 2012/2013 - coletiva de imprensa. São Paulo, setembro de 2012. Disponível em www.unica.com.br. Acesso em maio de 2013.

VEIGA FILHO, Alceu. Fatores explicativos da mecanização do corte na lavoura canavieira paulista. Informações Econômicas, São Paulo, v. 28, n. 3, p. 7-33, nov. 1998. Disponível em: http://www.iea.sp.gov.br/ download/tec1-1198.pdf. Acesso em: 28/11/2014. 